\title{
Left ventricular pseudoaneurysm after replacement of a Melody valve in the left atrioventricular valve position
}

Daniel A. Castellanos, MD, ${ }^{a}$ Robert D. B. Jaquiss, MD, ${ }^{b}$ and Poonam P. Thankavel, MD, ${ }^{a}$ Dallas, Tex

\footnotetext{
From the ${ }^{\mathrm{a}}$ Division of Cardiology, Department of Pediatrics, and ${ }^{\mathrm{b}}$ Pediatric Group, Department of Cardiothoracic Surgery, Children's Medical Center Dallas, University of Texas Southwestern Medical Center, Dallas, Tex. Disclosures: The authors reported no conflicts of interest.

The Journal policy requires editors and reviewers to disclose conflicts of interest and to decline handling or reviewing manuscripts for which they may have a conflict of interest. The editors and reviewers of this article have no conflicts of interest.

Received for publication Aug 30, 2020; accepted for publication Sept 17, 2020; available ahead of print Sept 24, 2020.

Address for reprints: Daniel A. Castellanos, MD, 1935 Medical District Dr, MC B3.09, Dallas, TX 75235 (E-mail: dcastell@alumni.nd.edu).

JTCVS Techniques 2020;4:248-50

2666-2507

Copyright $\odot 2020$ The Authors. Published by Elsevier Inc. on behalf of The American Association for Thoracic Surgery. This is an open access article under the CC BY-NC-ND license (http://creativecommons.org/licenses/bync-nd/4.0/).

https://doi.org/10.1016/j.xjtc.2020.09.015
}

\section{CASE PRESENTATION}

A female patient was born with partial atrioventricular septal defect, coarctation of the aorta, and multiple ventricular septal defects. At 8 days of life, she underwent coarctation repair followed by placement of a main pulmonary artery band at 3 weeks of age. After somatic growth was achieved, she underwent removal of the pulmonary artery band, fenestrated atrial septal defect repair, and closure of multiple ventricular septal defects at 10 months of age. Her postoperative course was complicated by severe left atrioventricular valve regurgitation and residual interventricular shunt, with unsuccessful attempts at valve repair and device closure of the ventricular septal defect at

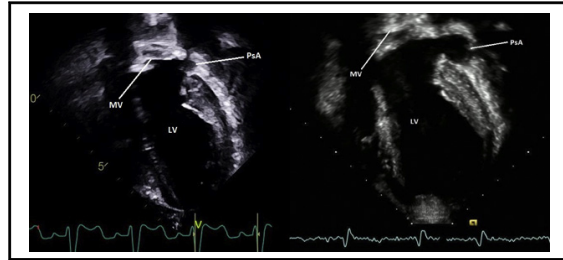

Left ventricular pseudoaneurysm after replacement of Melody valve in the mitral position.

\section{CENTRAL MESSAGE}

There is risk of left ventricular pseudoaneurysm development with replacement of the Medtronic Melody valve in the mitral valve position.

See Commentaries on pages 251 and 253.
10.5 months of age. At 11 months of age, a Melody valve (a Contegra valved conduit attached to a stent) was placed in the mitral position, which required eventual balloon dilation in the catheterization laboratory. She then relocated and established care at our institution at 2 years of age.

At 4 years of age, due to moderate regurgitation and moderate stenosis, she underwent repeat Melody valve balloon valvuloplasty. The procedure was complicated by worsened

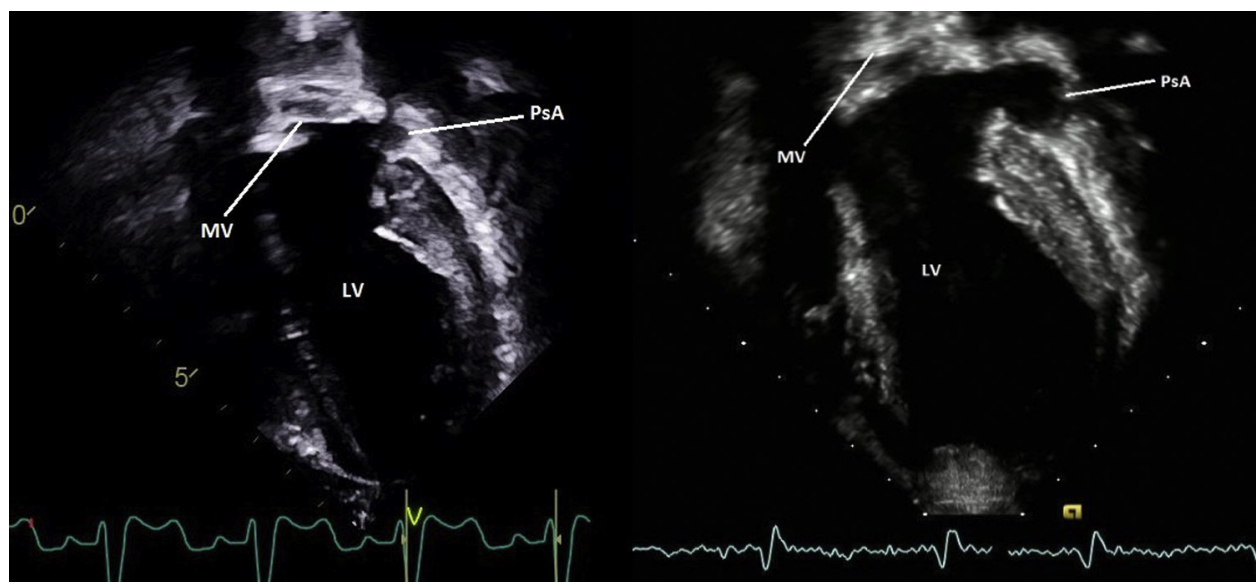

FIGURE 1. Left ventricular pseudoaneurysm progression after placement of a Melody valve in the left atrioventricular valve position, then 2 subsequent valve dilations, and finally surgical removal of the valve with replacement with a 19-mm St Jude Medical Regent mechanical heart valve. Apical 4-chamber views on transthoracic echocardiograms demonstrates the pseudoaneurysm at 1 (left) and 19 (right) months postoperatively. $M V$, Mitral valve; $L V$, left ventricle; $P s A$, pseudoaneurysm. 
valvar regurgitation (moderate to severe); thus, she underwent surgical replacement with a 19-mm Regent mechanical heart valve (St Jude Medical, St Paul, Minn) at 5 years of age. Postoperative transesophageal echocardiogram demonstrated no residual lesions, and her recovery was uneventful.

Routine follow-up with surveillance echocardiography demonstrated a well-functioning prosthetic valve with no stenosis nor regurgitation. One month postoperatively, a small left ventricular pseudoaneurysm was noted on the lateral posterior aspect of the left ventricle, just below the native mitral annulus and in close proximity to the prosthetic valve. Due to progressive enlargement of this pseudoaneurysm (Figure 1), the patient underwent left ventricular pseudoaneurysm repair 19 months after the $\mathrm{St}$ Jude valve placement. A cardiac computed tomography scan was obtained to delineate its relationship to the coronary arteries and to assist with operative approach. The pseudoaneurysm was noted to be near the circumflex coronary artery (Figure 2). At reoperation, due to intense scarring around the base of the heart, the pseudoaneurysm could not be visualized externally, and a left atrial incision was performed. The pseudoaneurysm opening was visualized through the prosthetic valve, with the most basal aspect of the ostium located 7 to $8 \mathrm{~mm}$ below the prosthetic valve ring. Repair of the defect was performed with a patch of bovine pericardium, working through the open valve. Postoperative transesophageal echocardiogram demonstrated normal prosthetic valve function and no residual flow into the aneurysm. Recovery was uneventful, and the patient remains well at 6-month postoperative follow-up. Verbal consent for publication was obtained by the patient's mother.

\section{DISCUSSION}

Left ventricular pseudoaneurysm after mitral valve replacement has been previously reported in the adult population and has been classified into various types based on anatomic location within the ventricle. ${ }^{1,2}$ Type 1 is a rupture located in the posterior atrioventricular groove, type 2 is a rupture in the posterior wall of the left ventricle at the base of the papillary muscle, and type 3 is a rupture in the area between the atrioventricular groove and papillary muscle. Our case is consistent with a type 3 pseudoaneurysm. Due to risk of progressive enlargement and subsequent rupture, surgical repair of the pseudoaneurysm is the recommended approach. An intracardiac approach has been recommended for type 1 and the external approach for types 2 and $3 .^{1-3}$ In our patient, the external approach was not feasible due to scarring and proximity of the pseudoaneurysm to the coronary artery. Intracardiac repair was possible without valve removal and replacement. Echocardiography was vital for diagnosis and surveillance, whereas computed tomography scan was helpful in demonstrating the relationship of the circumflex coronary artery to the pseudoaneurysm.

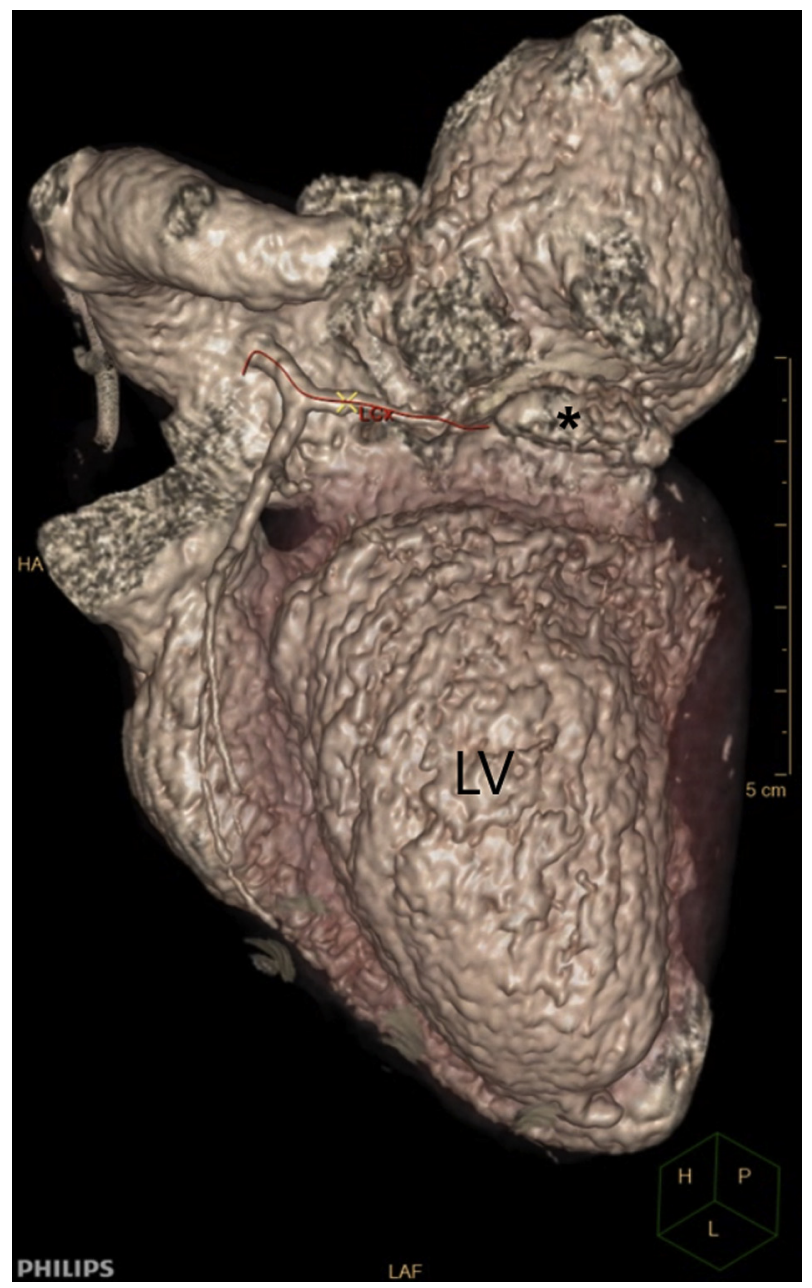

FIGURE 2. Computed tomography scan was obtained to delineate the relationship of the coronary artery to the left ventricular pseudoaneurysm. Three-dimensional computed tomography angiography reconstruction demonstrates the proximal left circumflex coronary artery, the pseudoaneurysm $(*)$, and the left ventricular cavity $(L V)$. The course of the left circumflex coronary artery was in close proximity to the pseudoaneurysm.

The use of Medtronic Melody valve in the left atrioventricular valve position is considered in infants and children when a small prosthesis is required that has the potential to be expanded with somatic growth. ${ }^{4}$ As the use of such valves becomes more popular, it is important to recognize the potential complications of a stented valve in the mitral position. Aggressive sharp surgical dissection to free the Melody valve from its surroundings at explantation may result in injury to the ventricular wall and such an injury may go unrecognized during the immediate perioperative period. Careful excision of the Melody valve during replacement along with echocardiographic surveillance for left ventricular pseudoaneurysm formation at followup is warranted. This case represents the first report of left ventricular pseudoaneurysm formation in a pediatric patient after Melody valve replacement. 


\section{References}

1. Treasure RL, Rainer WG, Strevey TE, Sadler TR. Intraoperative left ventricular rupture associated with mitral valve replacement. Chest. 1974;66:511-4.

2. Lanjewar C, Thakkar B, Kerkar P, Khandeparkar J. Submitral left ventricular pseudoaneurysm after mitral valve replacement: early diagnosis and successful repair. Interact Cardiovasc Thorac Surg. 2007;6:505-7.
3. Björk VO, Henze A, Rodriguez L. Left ventricular rupture as a complication of mitral valve replacement. J Thorac Cardiovasc Surg. 1977;73:14-22.

4. Quiñonez LG, Breitbart R, Tworetsky W, Lock JE, Marshall AC, Emani SM. Stented bovine jugular vein graft (Melody valve) for surgical mitral valve replacement in infants and children. J Thorac Cardiovasc Surg. 2014;148: 1443-9. 